\title{
Correction to : Coordinate expression of pan-neuronal and functional signature genes in sympathetic neurons
}

\author{
U. Ernsberger ${ }^{1}$ - M. Kramer $^{1} \cdot$ K. Tsarovina ${ }^{2} \cdot$ T. Deller $^{1} \cdot$ H. Rohrer $^{1}$
}

Published online: 10 November 2017

(C) Springer-Verlag GmbH Germany 2017

Correction to: Cell Tissue Res (2017) 370:227-241

https://doi.org/10.1007/s00441-017-2688-7

The published online version contains mistakes. We apologize for errors in the lettering of Fig. $3 \mathrm{~d}$ and would also like to correct the legend of Fig. $2 \mathrm{~b}$.

The correct label for the y-axis in Fig. 3d is "VMAT2 (black), Th (red) and Tubb3 (blue) mRNA molecules". We also corrected the numbers in the y-axis. A correct version of Fig. 3 is given below:

The online version of the original article can be found at https://oi.org/ 10.1007/s00441-017-2688-7

\footnotetext{
H. Rohrer

rohrer@med.uni-frankfurt.de

1 Institute of Clinical Neuroanatomy, Goethe University Frankfurt/M, Theodor-Stern-Kai 7, 60590 Frankfurt/M, Germany

2 Max-Planck-Institute for Brain Research, Developmental

Neurobiology, Max-von-Lauestr. 4, 60438 Frankfurt/M, Germany
} 

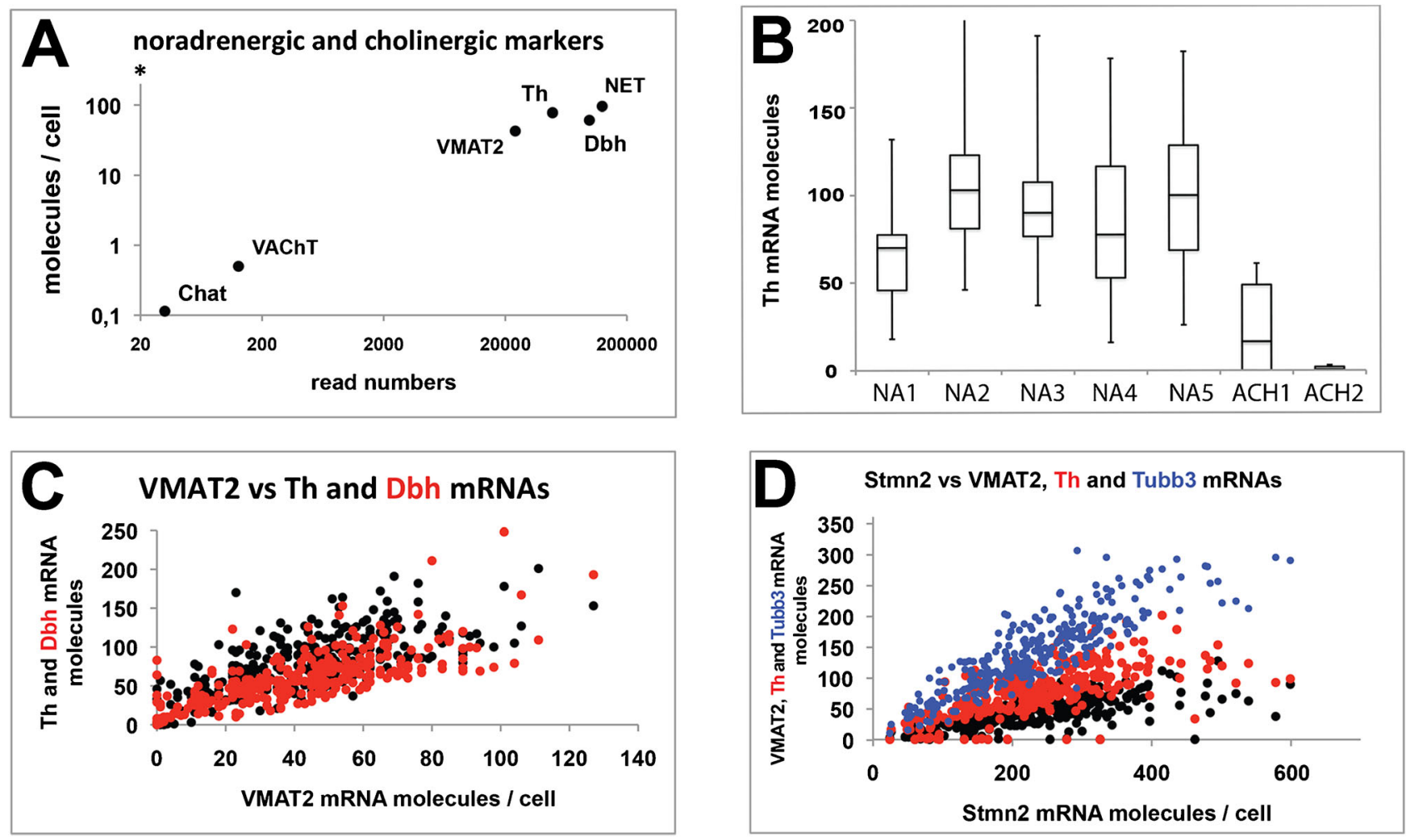

The correct legend for Fig. $2 b$ is "Most cells with high neurofilament $\mathrm{M}$ levels show high noradrenergic marker expression but lack VAChT transcripts." 